\title{
D-depth profiling in as-implanted and annealed Li-based breeder blanket ceramics
}

\author{
Elisabetta Carella , Maria Gonzalez , Raquel Gonzalez-Arrabal
}

\section{H I G H L I G H T S}

- Three solid breeder blanket candidates were D-implanted and characterized by NRA at different annealing temperatures.

- Lithium containing silicate and titanate ceramics with ratio $2 \mathrm{Li}: \mathrm{Si}, 3 \mathrm{Li}: \mathrm{Si}$ and $1 \mathrm{Li}: T i$ were fabricated.

- The fabricated ceramics exhibit different porosity, grain size and density.

- The ceramics were implanted with $\mathrm{D}$ : a complete outgas was observed at $T \geqslant 200{ }^{\circ} \mathrm{C}$.

- Surface is crucial for the release kinetics and grain boundaries represent an alternative path to porous for diffusion.

\begin{abstract}
A B S T R A C T
In future power plants (i.e. DEMO), the nuclear fusion of hydrogen isotopes will be used for energy production. The behaviour of hydrogen isotopes in lithium-enriched ceramics for breeder blankets (BBs) is one of the most important items to be understood.

In this paper we present the chemical, microstructural and morphological features of $\mathrm{Li}_{4} \mathrm{SiO}_{4}, \mathrm{Li}_{2} \mathrm{TiO}_{3}$ and a third ceramic candidate with a higher Li:Si proportion (3:1), implanted with $\mathrm{D}$ at an energy of $100 \mathrm{keV}$ and at room temperature at a fluence of $1 \times 10^{17} \mathrm{~cm}^{2}$.

The D depth-profile in as-implanted and annealed ceramics (at $T \leqslant 200^{\circ} \mathrm{C}$ ) was characterised by Resonance Nuclear Reaction Analysis (RNRA). The RNRA data indicate that the total amount of D is retained at room temperature, while annealing at $100^{\circ} \mathrm{C}$ promotes $\mathrm{D}$ release and annealing at $T \geqslant 150^{\circ} \mathrm{C}$ drives $\mathrm{D}$ to completely desorb from all the studied ceramics. $D$ release will be discussed as a function of the microstructurural and morphological features of each material.
\end{abstract}

\section{Contents}

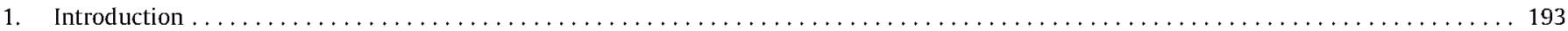

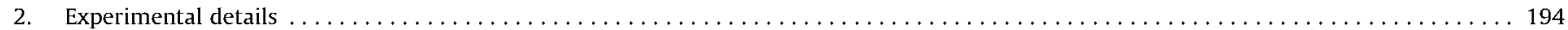

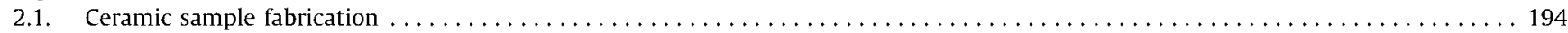

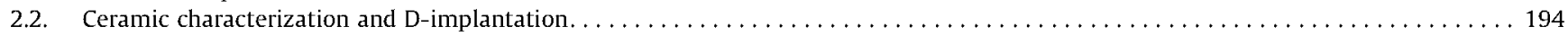

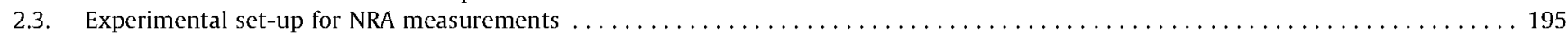

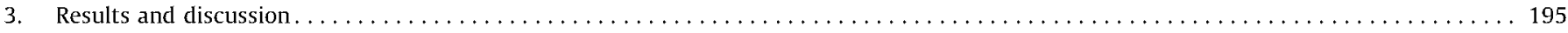

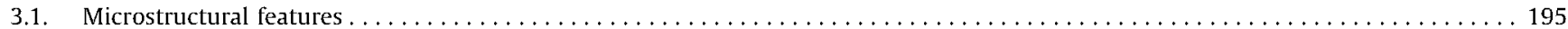

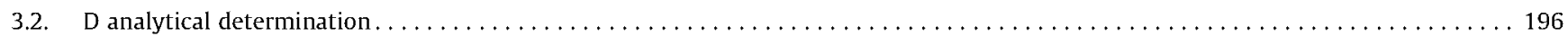

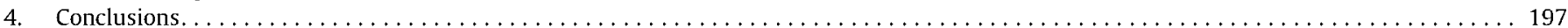

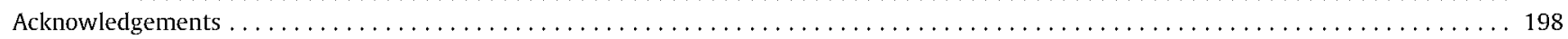

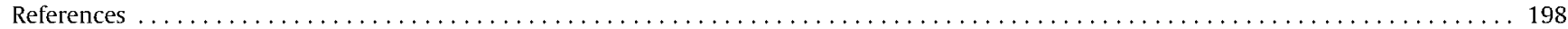

\section{Introduction}

One of the main parameters to be considered in the design of a nuclear fusion reactor is the supply of tritium ( $T$ ) fuel to feed the
$\mathrm{D}+\mathrm{T} \rightarrow{ }^{4} \mathrm{He}(3.56 \mathrm{MeV})+n(14.03 \mathrm{MeV})$ reaction. In present fusion reactor designs Tritium production and recovering takes place in the breeder blanket, which also converts the neutron energy into heat and protects the vacuum vessel against radiation-induced damage.

Because of their properties (among others: high radiation resistance, low tritium retention and high tritium generation), 
Li-based ceramics are one of the most promising materials for breeder blankets [1]. In these materials the Tritium originates from the following nuclear reactions ${ }^{6} \mathrm{Li}(n, \alpha) \mathrm{T}$ or ${ }^{7} \mathrm{Li}(n, n \alpha)$ $\mathrm{T}$ [2] taking place when the ceramics are irradiated with neutrons. The lost of T from neutron-irradiated lithium ceramics involves its diffusive motion within the solid and its subsequent release from the ceramic surface. The understanding of $T$ behaviour (retention and release) in the bulk and at the surface of these porous materials is crucial in order to achieve a reactor self-sustainable operation (Tritium Breeder Ratio, TBR higher than 1.15 [3]). Previous experimental and simulated results [4] evidence that both Tritium transport and release in Li-based ceramics are complex processes involving, among others: grain boundary and inter-granular diffusion, absorption and desorption at the gas/solid interfaces, diffusion along the interconnected porous, and surface reactions. Moreover an additional factor, which has to be considered when studying $\mathrm{T}$ behaviour in irradiated materials, is the evolution of the microstructure during irradiation with energetic ions, neutrons and electrons [5]. A good number of in situ T release experiments testing several different irradiated materials have been carried out at different laboratories [6-9], the conclusions being that processes involved in the annihilation of radiation defects seem to play an important role to establish the $\mathrm{T}$ recovering system and the release behaviour.

Because of the high T activity, its volatile and its long decay time which lead to complex and rigid safety procedures, in order to analyse $\mathrm{T}$ behaviour, reactor irradiation tests are traditionally simulated by ion implantation of other light species such as $\mathrm{H}$, D or ${ }^{3} \mathrm{He}[10]$ which are easier to handle.

Few are the publications studying hydrogen isotopes behaviour in ceramics for fusion breeder applications $[2,4,11,12]$. If some are the papers reporting that $\mathrm{T}$ release is limited by grain diffusion [13], giving the idea that the release is mainly driven by internal diffusion processes related to the materials composition or microstructure, other publications highlight the improvement obtained by using argon or helium mixtures with low concentration of hydrogen as the purge gas [14].

In an attempt to better understand the tritium transport in fusion breeding blankets during operation with the help of a comparable $\mathrm{H}$ isotope as a trace, the aim of this work is to study the D thermal behaviour in lithium ceramics, promising candidates for fusion breeding blankets. For this purpose a set of porous lithium ceramics with different chemical compositions $\left(\mathrm{Li}_{2} \mathrm{TiO}_{3}, \mathrm{Li}_{4} \mathrm{SiO}_{4}\right.$ and a 3:1 Lithium content silicate) and microstructures (porosity and grain size) were fabricated and characterized. Next the samples were Room temperature implanted with a $100 \mathrm{keV} \mathrm{D}_{2}$ ion-source. Since the operational temperature of a solid breeding material has been estimated to be in the range from $300^{\circ} \mathrm{C}$ to $900^{\circ} \mathrm{C}$ [15], the D desorption profiles were then studied as a function of temperature by Resonance Nuclear Reaction Analysis (RNRA), using the D $\left({ }^{3} \mathrm{He}, \mathrm{p}\right){ }^{4} \mathrm{He}$ nuclear reaction up to the total D outgas. Considering fusion interests towards the search of solid breeders with the highest possible lithium contents, the D thermal diffusion is then discussed comparatively in terms of the materials composition, microstructure and release temperature.

\section{Experimental details}

\subsection{Ceramic sample fabrication}

Two silica-based ceramics were synthesized using $\mathrm{SiO}_{2}$ gel and lithium citrate powder $\left(\mathrm{Li}_{3} \mathrm{C}_{6} \mathrm{H}_{5} \mathrm{O}_{7}\right)$. The precursors were manually mixed at room temperature during 20 min until homogeneity, calcined in an open oven at $250{ }^{\circ} \mathrm{C}$ for $12 \mathrm{~h}$, and then milled for $1 \mathrm{~h}$ using a planetary ball-mill and mixed with ethanol, to reduce particle size. The grounded powders were dried in a Rotavapor (R-210) and calcined again in air at $750^{\circ} \mathrm{C}$ for $10 \mathrm{~h}$. The entire process was repeated until a last calcination at $950^{\circ} \mathrm{C}$ for $10 \mathrm{~h}$. The same synthesis method was followed for the fabrication of the two silicabased ceramics, only varying the Li-to-Si proportion to achieve the $2 \mathrm{Li}: \mathrm{Si}$ and $3 \mathrm{Li}: \mathrm{Si}$ compounds.

On the other hand, lithium titanate samples (MTi or 1Li:Ti) were fabricated starting from commercial $99.9 \%$ purity Alfa Aesar powders.

Then, calcined and milled powders from all compositions were isostatically pressed at $250 \mathrm{MPa}$ as $10 \mathrm{~mm}$ diameter bars and cut into discs of about $2 \mathrm{~mm}$ thickness. With the aim to reach the best compromise between density and good crystallinity, pellets were then sintered in air at different temperatures (see Table 1) with a $5^{\circ} \mathrm{C} / \mathrm{min}$ ramp, during $2 \mathrm{~h}$ of dwell.

\subsection{Ceramic characterization and D-implantation}

Structural characterization of the as-fabricated samples was carried out by X-ray diffraction (XRD) using a Philips X-PERTMPD diffractometer with a $\mathrm{Cu} K \alpha$-radiation source. The XRD measurements were performed in Bragg-Brentano geometry [16].

$\mathrm{Hg}$ intrusion porosimetry is frequently used to characterize the pore structure of ceramic materials. Using this technique, the porosity distribution curve as a function of the apparent size of the accessed pores under increasing $\mathrm{Hg}$ pressure [17] was obtained (see Fig. 2) and the total apparent porosity of each sample was calculated.

Sample morphology was studied by scanning electron microscopy (SEM) using a MICRO SEM S-2500 HITACHI microscope. Prior to SEM observation, sintered specimens were polished down to a $1 \mu \mathrm{m}$ diamond finish and then thermally etched during $30 \mathrm{~min}$ at temperatures slightly lower than the sintering one to reveal the grain boundaries. Since samples are electrical insulators, surfaces were covered by an e-beam deposited carbon layer, which prevents the samples to get charged.

Polished and characterized pellets were room temperature implanted at energy of $100 \mathrm{keV}$ using the $\mathrm{D}_{2}{ }^{+}$beam of the UCM (Madrid, Spain) implantation facility. The total accumulated fluence was about $3 \times 10^{17} \mathrm{~cm}^{-2}$. Using the obtained experimental densities, the maximum depths for the implanted ions were calculated by the SRIM Monte Carlo code [18] to be $1.32 \mu \mathrm{m}$ for $\mathrm{Li}_{4} \mathrm{SiO}_{4}$ $1.1 \mu \mathrm{m}$ for $\mathrm{Li}_{6} \mathrm{SiO}_{5}$ and $0.96 \mu \mathrm{m}$ for $\mathrm{Li}_{2} \mathrm{TiO}_{3}$. After implantation samples were stored under environmental conditions (about $30 \%$ of relative humidity during autumn months in Madrid, Spain) at room temperature during 3 days before $\mathrm{D}$ depth profiling analysis.

Table 1

Sintering conditions and main phases for the three studied samples.

\begin{tabular}{|c|c|c|c|}
\hline Compositions & 1Li:Ti & 2Li:Si & 3Li:Si \\
\hline $\begin{array}{l}\text { Sintering temperature/dwell time }\left({ }^{\circ} \mathrm{C} / \mathrm{h}\right) \\
\text { Present phases }\end{array}$ & $\begin{array}{l}1150 / 2 \\
(100 \%) \mathrm{Li}_{2} \mathrm{TiO}_{3}\end{array}$ & $\begin{array}{l}950 / 2 \\
(47.8 \%) \mathrm{Li}_{2} \mathrm{SiO}_{3},(23.4 \%) \mathrm{Li}_{4} \mathrm{SiO}_{4},(3 \%) \mathrm{SiO}_{2}{ }^{\mathrm{a}}\end{array}$ & $\begin{array}{l}1000 / 2 \\
(59.4 \%) \mathrm{Li}_{4} \mathrm{SiO}_{4},(38.8 \%) \mathrm{Li}_{2} \mathrm{SiO}_{3} \text { and }(1.8 \%) \mathrm{SiO}_{2}\end{array}$ \\
\hline
\end{tabular}

a Other phases (crystalline and amorphous) and secondary reaction products. 


\subsection{Experimental set-up for NRA measurements}

The D depth profiles were characterised by means of Resonance Nuclear Reaction Analysis (RNRA) at the KUL-Leuven tandem accelerator facility by using the $\mathrm{D}\left({ }^{3} \mathrm{He}, \mathrm{p}\right){ }^{4} \mathrm{He}[19]$ nuclear reaction. Measurements were carried out with a ${ }^{3} \mathrm{He}$ ion beam impinging the sample surface at normal incidence. This reaction has a broad resonant peak at a ${ }^{3} \mathrm{He}$ energy of $0.63 \mathrm{MeV}$, therefore the beam energy was varied in the range from 0.64 to $1.5 \mathrm{MeV}$ in order to cover the whole projected range. Protons were detected by a glancing PIPS (Passivated Implanted Planar Silicon) Canberra detector with an active area of $50 \mathrm{~mm}^{2}$ located at $142^{\circ}$ from the beam direction. A $13 \mu \mathrm{m}$ Mylar foil was placed in front of the detector in order to stop other light elements (i.e. $\alpha$ particles) arising from the nuclear reaction. The total accumulated dose for each spectrum was $5 \mu \mathrm{C}$. The ${ }^{3} \mathrm{He}$ beam spot and the current were selected to be $1 \mathrm{~mm}^{2}$ and $\sim 10 \mathrm{nA}$, respectively. Previous tests were performed to assure reliable depth profiling measurements.

$\mathrm{D}$ depth profiles were registered at increasing temperatures (Room $\mathrm{T}, 100^{\circ} \mathrm{C}, 150^{\circ} \mathrm{C}$ and $200^{\circ} \mathrm{C}$ ). Temperature was measured and controlled using a K-type thermocouple fixed to the furnace located at the back of the sample-holder, an experimental set-up designed at the KUL laboratories. This configuration allowed in situ measuring the spectra of nuclear reactions, while the annealing treatments were carried out.

The $\mathrm{D}$ concentration as a function of depth was determined by comparing measured and simulated RNRA spectra. For simulations the commercial computer code SIMNRA was used [20]. The selected cross section for the calculations was that reported by Alimov et al. [19], whose measurements were performed at a scattering angle of $135^{\circ}$. In this experiment, the angle was set at $142^{\circ}$, however according to Möller and Besenbacher [21] within ${ }^{3} \mathrm{He}$ energy range $0.64-1.2 \mathrm{MeV}$ the nuclear reaction is almost angle independent. A tailor-made program implemented in the $\mathrm{Nu}$ clear and Radiation Physics Department at the KUL was used to calculate the recorded proton yield.

\section{Results and discussion}

\subsection{Microstructural features}

Pointing their final application as fusion breeder blankets, the sintering conditions used for the fabricated ceramic bodies were established to achieve porous ceramics with stable crystalline structures. Prior to D implantation and light ion depth profiling,

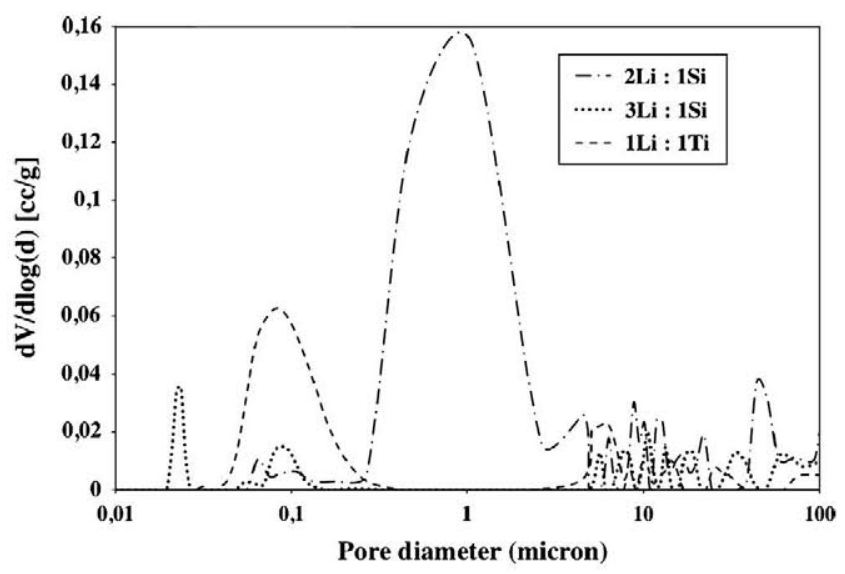

Fig. 2. Comparative pore distribution curves experimentally obtained for the three studied lithium ceramics by using $\mathrm{Hg}$ inclusion porosimetry.

crystalline phases and experimental densities of the three ceramic samples with variable Li-to-Si ratio and Ti-matrix were firstly characterized. In addition, the ceramic microstructures after sintering were characterized by their open porosity and pore size distribution in order to properly discuss the $\mathrm{D}$ transport processes.

As determined by XRD analysis (see Fig. 1 and Table 1), the lithium titanate presents a unique phase $\left(\mathrm{MTi} \mathrm{Li}_{2} \mathrm{TiO}_{3}\right)$ with a high crystallinity. For a Li-to-Si ratio of $2: 1, \mathrm{Li}_{2} \mathrm{SiO}_{3}(\mathrm{MSi})$ and $\mathrm{Li}_{4} \mathrm{SiO}_{4}$ (OSi) crystallographic phases are observed to co-exist with a mixture of $\mathrm{SiO}_{2}$ and $\mathrm{Li}_{2} \mathrm{CO}_{3}$ phases (secondary reaction products). In the case of the ceramic material with a $\mathrm{Li}: \mathrm{Si}$ ratio of $3: 1$, only $\mathrm{Li}_{4-}$ $\mathrm{SiO}_{4}$ and $\mathrm{Li}_{2} \mathrm{SiO}_{3}$ are the phases presented. The effect of Li excess seems to be the explanation for the precipitation of the new orthosilicate phase in higher proportions.

The pore size distributions for the three sintered materials are estimated by using the mercury intrusion method (Fig. 2). These experimental porosimetry measurements correspond to the microstructures shown in Fig. 3. Since the bulk sample volume is an experimental data obtained from porosimetry, the experimental density and porosity values could be then calculated with high accurate (see Table 2).

A wide range of open-pore diameters is identified for the three samples after sintering. $1 \mathrm{Li}: \mathrm{Ti}$ and $2 \mathrm{Li}: \mathrm{Si}$ compositions show narrow pore distributions where the majority of the pores have diameters below the micron size $(0.08$ and $0.9 \mu \mathrm{m}$, respectively). The presence of narrower pore size distributions of smaller pore
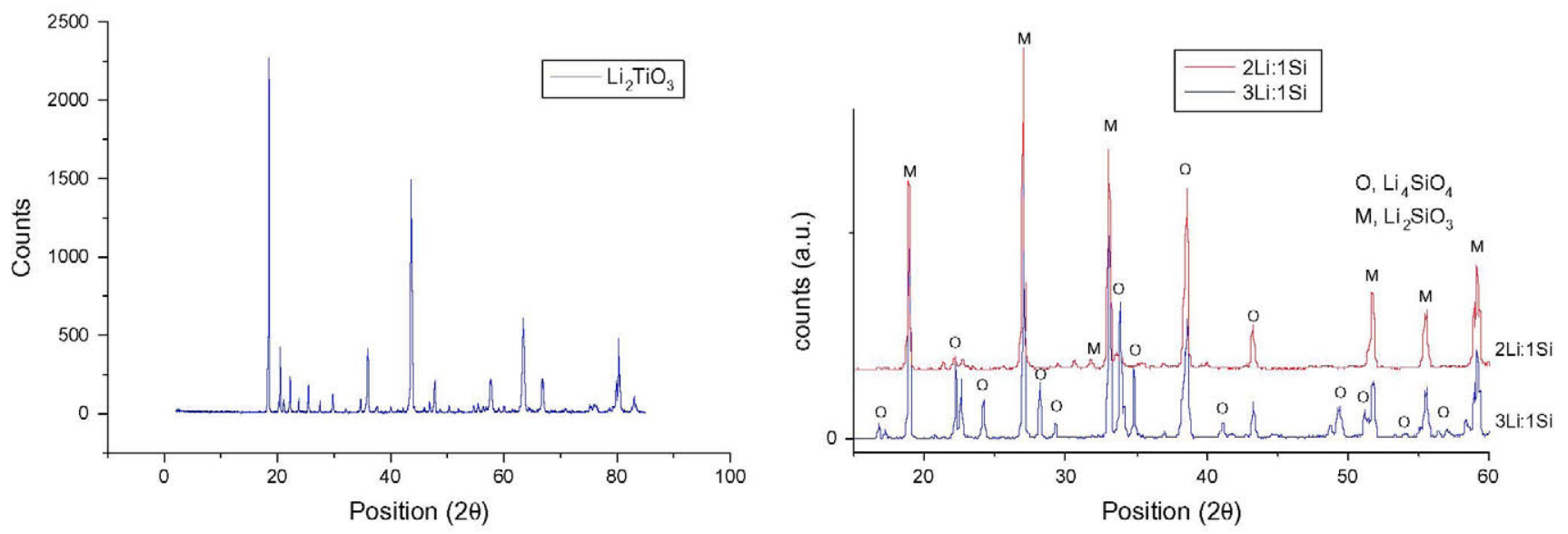

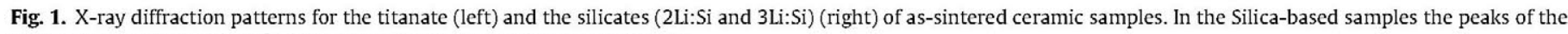
two main phases are identified like $O$ (Orthosilicate) and M (Metasilicate). 

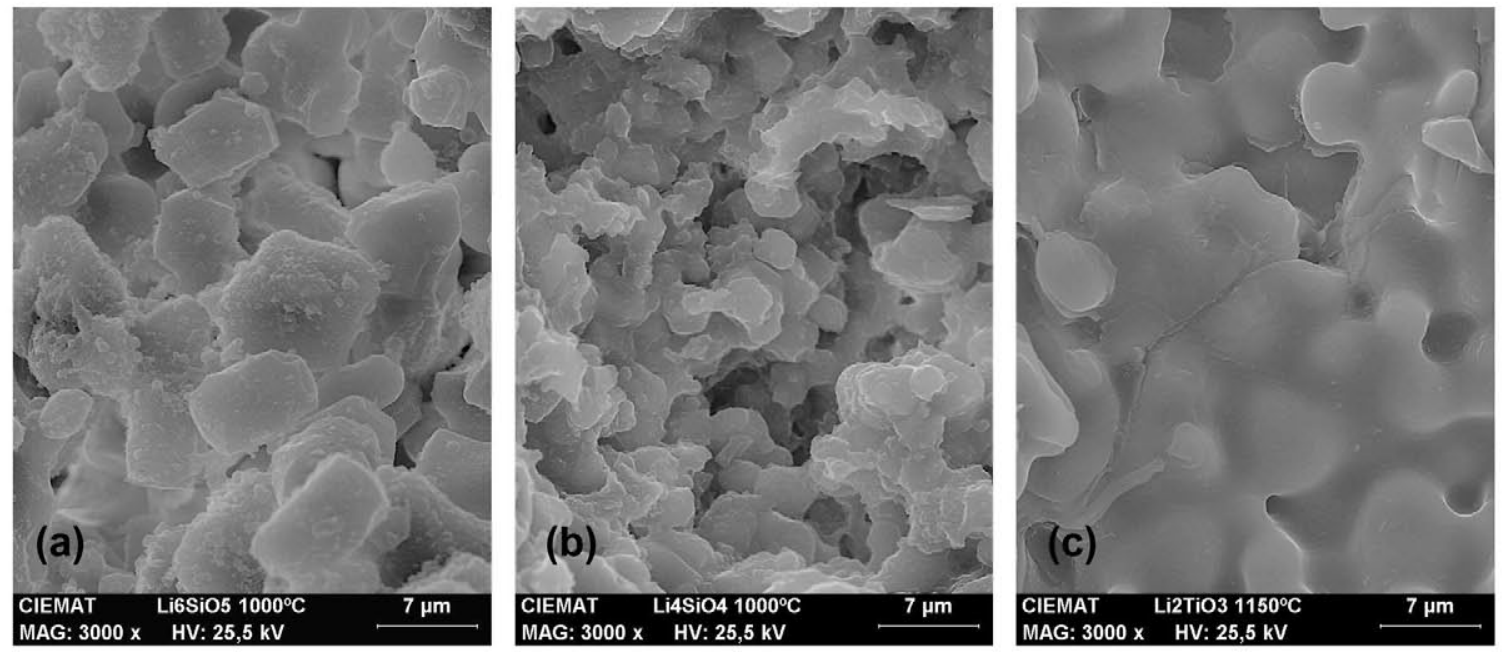

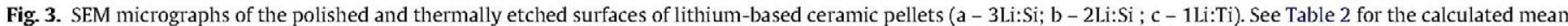
grain sizes.

Table 2

Main microstructure characteristics for the ceramic specimens.

\begin{tabular}{llll}
\hline Material & 1Li:Ti & 2Li:Si & $3 \mathrm{Li}: \mathrm{Si}$ \\
\hline $\mathrm{D}_{\text {th }}$ : theoretical density $(\mathrm{g} / \mathrm{cc})$ & 3.43 & 2.24 & 2.17 \\
$\mathrm{D}_{\text {exp }}$ : experimental density $(\mathrm{g} / \mathrm{cc})$ & 2.7 & 1.6 & 2.05 \\
Density (\% T.D.) & 78 & 73 & 94.5 \\
Porosity (\%) & 22 & 27 & 5.5 \\
Main open pore diameters $(\mu \mathrm{m})$ & 0.08 & 0.9 & $0.1 ; 0.025$ \\
Grain size $(\mu \mathrm{m})$ & 3 & 2 & 0.15 and 6 (bimodal) \\
\hline
\end{tabular}

diameters is the explanation for a better-densified material, which is the case of the titanate material. On the other hand, the $3 \mathrm{Li}: \mathrm{Si}$ composition shows a distribution curve where two more frequent pore diameters are stressed (see Table 2 ) corresponding to pores of nanometer size $(0.1$ and $0.025 \mu \mathrm{m})$.

When comparing the SEM images of the as-sintered fresh fractures shown in Fig. 3 marked morphological differences are appreciated between samples. The mean grain sizes are estimated to be about 1.5 and $2 \mu \mathrm{m}$ for the $1 \mathrm{Li}$ :Ti and the $2 \mathrm{Li}: \mathrm{Si}$ ceramics, respectively. The observed microstructures are in agreement with those reported in the literature for similar sintering conditions [22,23]. On the other hand, a bimodal grain size distribution is observed for the 3Li:Si sample, where grains with an average grain size of $0.15 \mu \mathrm{m}$ are shown decorating the $6 \mu \mathrm{m}$ sized grains.

The explanation to the higher amount of the OSi phase in the 3Li:Si composition may be found in the excess of lithium carbonate as the reactant and due to the slight superior temperature during sintering, as expected from the phase diagram [24]. Considering that the grain size for the OSi and MSi phases are quite similar, the secondary phases could be the explication for the different size of grains found. The crystallization of the OSi phase in the $3 \mathrm{Li}: \mathrm{Si}$ composition in submicron grains may be explained due to the sintering temperature since for sintering temperatures of $1020^{\circ} \mathrm{C}$ the grain size is still reported to be very small $(2-3 \mu \mathrm{m})[25,26]$.

The very high density $\left(94.5 \% \mathrm{D}_{\mathrm{th}}\right)$ in case of the $3 \mathrm{Li}$ :Si composition is better described by the presence of these very small particles of a different structure responsible for the existence of the $0.025 \mu \mathrm{m}$ sized pores. The existence of so-small sized grains, which precipitates in the interstitial voids left by the bigger ones, allows a better packing resulting in a sintered material with reduced porosity. The existence of nanograins accompanying the main crystalline structure is then a definitive method to reduce porosity.

For Tritium recovery purposes, ceramic breeders having the 85 $90 \%$ of true density and open porosity are required. Moreover, a uniform small grain size distribution (having diameters smaller than $10 \mu \mathrm{m}$ ) should be achievable since the activation energy for grains diffusion is higher compared to that along grain boundaries [11]. After sintering, all samples here studied exhibit the interconnected porous network expected for breeder applications. Therefore, the achieved microstructures as fitting these fusion requirements could initially be considered optima for the easy transport of the implanted D.

\section{2. $D$ analytical determination}

The deuterium depth profiles are characterized by means of RNRA. It is worthwhile to mention that in order to determine the $\mathrm{D}$ concentration in a reliable way, background spectra were measured deep into the sample $(1.5 \mathrm{MeV} \sim 3.27 \mu \mathrm{m})$ where no implanted $\mathrm{D}$ is expected to be.

The deuterium concentration as a function of depth and temperature calculated from SIMNRA after background subtraction is shown in Fig. 4 for the three studied samples.

Clear differences between the measured and the simulated depth profiles, by using the SRIM Monte Carlo code (not shown), are observed. These differences, present in the whole measured temperature range might be mainly due to both the deuterium diffusion taken place even at room temperature and to the poor depth resolution associated to the broad resonance peak.

The estimated (implantation fluence) and measured (RNRA) total amount of D in as-implanted samples is almost the same, which indicates that, even when D diffusion occurs at RT, D does not significantly release from the samples when storing them three days under environmental conditions.

In general, the D concentration for all the as-implanted samples is significantly higher at the surface region than deeper into the samples, which indicates the influence of surface on D retention. Moreover, the deuterium concentration notably decreases for all the samples when increasing depth. Annealing at $T<150^{\circ} \mathrm{C}$ promotes $\mathrm{D}$ release from all ceramics. For annealing temperatures $\geqslant 150^{\circ} \mathrm{C}$, the $\mathrm{D}$ concentration is negligible for all the samples, indicating that at these temperatures deuterium is completely outgassed.

In order to have a clearer picture, the D concentration as a function of depth was evaluated into the whole samples as well as in two separate regions: the surface and the bulk. The different D distribution, calculated by the average value of the $\mathrm{D}$ atomic concentration measured for depths below $200 \mathrm{~nm}$ (surface region) and 

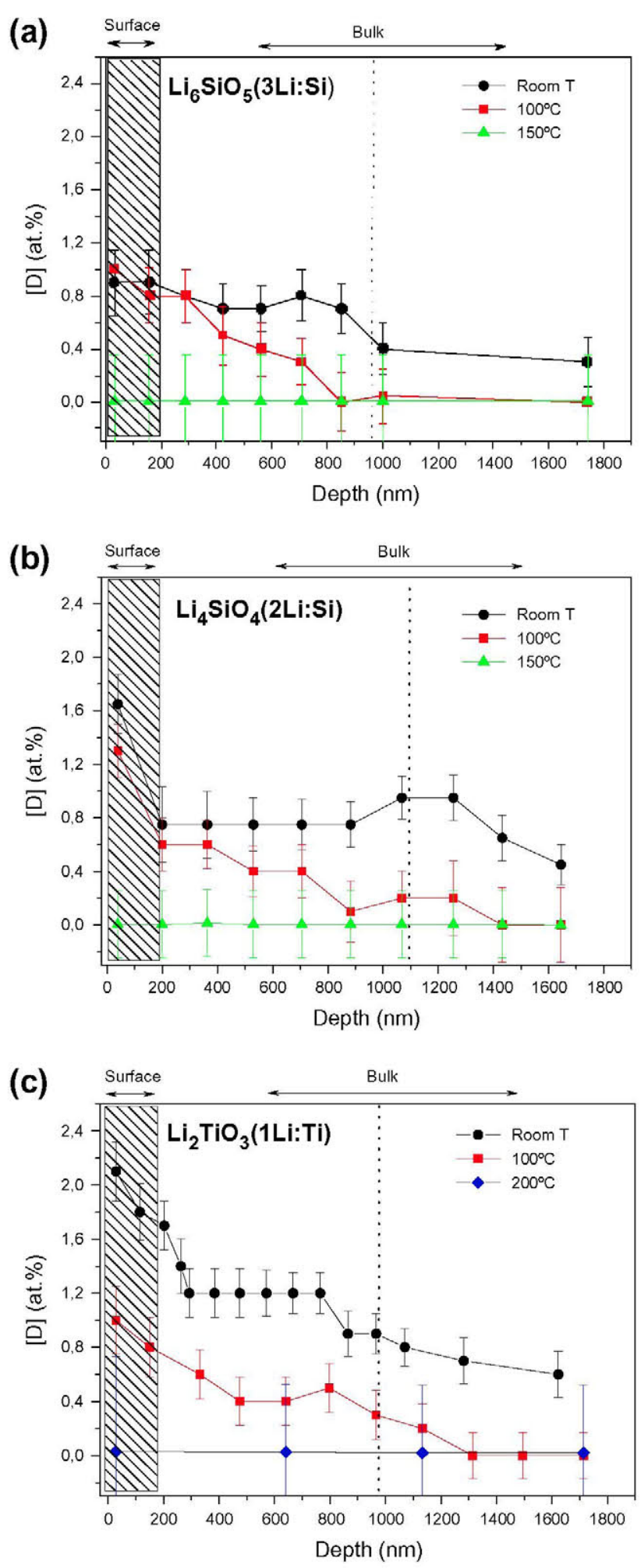

Fig. 4. Deuterium depth profiles in $\mathrm{Li}_{6} \mathrm{SiO}_{5}$ (3Li:Si) (a), $\mathrm{Li}_{4} \mathrm{SiO}_{5}$ (2Li:Si) (b) and $\mathrm{Li}_{2} \mathrm{TiO}_{3}$ (2Li:Ti) (c) samples, measured at different temperatures. The dot line represents the expected SRIM maximum for the material and the implantation ion energy. Sintering ceramic conditions and microstructural features are listed in Tables 1 and 2 .

from $200 \mathrm{~nm}$ to $1700 \mathrm{~nm}$ (bulk region) is shown in Fig. 5. As reported elsewhere [11], the breeder microstructure has a very strong influence on D behaviour. A different D behaviour is here observed when annealing the titanate and the silicates samples.

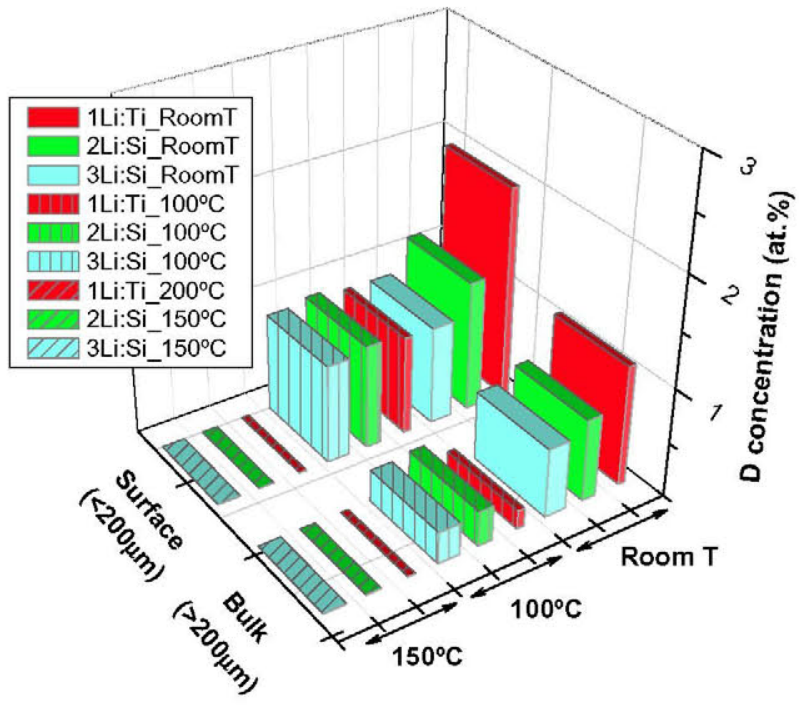

Fig. 5. Distribution of D concentration along sample depth calculated from the NRA analysis at several temperatures in the three Breeder Blanket candidate materials studied. Datas calculated from the average values (Fig. 4) found in the two regions: surface $(<200 \mathrm{~nm})$ and bulk (>200 $\mathrm{nm})$.

Annealing reduces the $\mathrm{D}$ concentration at all depths for the titanate. However, for the silicates, annealing decreases the D concentration in the bulk whereas it remains almost unchanged at the surface. At room temperature, the largest D concentration is measured (see Fig. 4) at the surface for the titanate ceramic $(2.1 \pm 0.2$ at.\%) whereas significantly lower D concentrations were measured for the lithium-rich compounds $(1.6 \pm 0.2$ at.\% for the $2 \mathrm{Li}: \mathrm{Si}$ and $1.0 \pm 0.2$ at.\% for the $3 \mathrm{Li}: \mathrm{Si}$ ). Such difference in the D concentration at the surface between both titanate and silicate samples is almost negligible after annealing (see Fig. 5). These results suggest that ceramics microstructure and/or chemical composition are playing an important role in the temperature-driven $\mathrm{D}$ transport, in close agreement with the literature $[2,4,11,12]$ that reports the strongly dependence of hydrogen isotopes behaviour on the materials composition or microstructure, which is favoured on porous materials.

From the above results it must be stressed that materials having very different microstructural characteristics but similar chemical composition show comparable elemental distributions in depth and at increasing temperatures. In particular the 3Li:Si sample, having so low remaining porosity (just $5.5 \%$ of porosity compared to that of the other two poorly densified materials), still allows the implanted D to be released. Since this sample has smaller grains in the sub- $\mu \mathrm{m}$ range and therefore a larger density of grain boundaries than those with higher porosity $\left(\mathrm{Li}_{4} \mathrm{SiO}_{4}, \mathrm{Li}_{2} \mathrm{TiO}_{3}\right)$ suggests that grain boundaries might play a similar role than porous for $\mathrm{D}$ diffusion. These results agree with those previously reported by Federici et al. [11] and by Bertone [27] who model the T transport in lithium ceramics by assuming a rather favourable and not rate controlling grain boundary diffusion.

\section{Conclusions}

The $\mathrm{D}$ depth distribution and thermal release have been studied by RNRA in three different candidates as solid breeder blanket: $\mathrm{Li}_{4-}$ $\mathrm{SiO}_{4}, \mathrm{Li}_{2} \mathrm{TiO}_{3}$ and a third one with a higher $\mathrm{Li}$ :Si proportion (3:1). Relevant correlations with the ceramic microstructural and morphological features (porosity, pore size distribution and grain size) have been found. 
Clear differences between measured and simulated (by the SRIM Monte Carlo code) profiles are observed which may be mainly due to both the deuterium diffusion taken place even at room temperature and to the poor depth resolution associated to the broad resonance peak.

Annealing at temperatures as low as $100^{\circ} \mathrm{C}$ promotes $\mathrm{D}$ release from all studied samples while at temperatures equal and higher than $150^{\circ} \mathrm{C}$ drives the whole $\mathrm{D}$ to be completely released from all the studied ceramics. It can be concluded that the $\mathrm{D}$ atomic concentration is significantly higher at the surface than in the bulk, i.e. $1.95 \%$ vs $1.11 \%$ for $1 \mathrm{Li}: \mathrm{Ti}$, and $1.20 \%$ vs $0.75 \%$ for $2 \mathrm{Li}: \mathrm{Si}$ in the as-implanted conditions, indicating that the ceramics surface play an important role in the $\mathrm{D}$ release.

By comparing $\mathrm{D}$ release data for samples with high porosity and low grain boundary density to those for samples with low porosity and high grain boundary density, it can concluded that grain boundary might be an alternative path to porous for $\mathrm{D}$ diffusion.

Since in actual breeder-blanket designs (i.e. the European HCPB concept) the operational temperature will be limited to $900^{\circ} \mathrm{C}$ [15], the presented results indicate that Li-based ceramics are very promising candidates for breeder applications. However further investigations of light species behaviour in damaged $\left(e^{-}, n\right.$ or $\gamma$ irradiated) ceramics might be carried out in order to achieve more accurate conclusions.

\section{Acknowledgements}

This work has been supported by the European Community as an Integrating Activity Support of Public and Industrial Research Using Ion Beam Technology (SPIRIT) under EC Contract No. 227012.

The authors want to thank Miss Montserrat Martín and Dr. Qiang Zhao for their help in these experiments.

\section{References}

[1] M.Y.P. Zmitko et al., J. Nucl. Mater. 417 (2011) 678-683.

[2] C.E. Jonson, J. Nucl. Mater. 270 (1-2) (1999) 212-220.

[3] M.E. Sawan, M.A. Abdou, Fus. Eng. Des. 81 (2006) 1131-1144.

[4] R.E. Avila, J.C. Jiménez, J. Nucl. Mater. 405 (2010) 244-251.

[5] J. Vanderlaan et al., J. Nucl. Mater. 283-287 (2000) 99-109.

[6] M. Oyaidzu et al., J. Nucl. Mater. 329-333 (2004) 1313-1317.

[7] C. Kang et al., J. Nucl. Mater. 412-1 (2011) 62-65.

[8] G. Piazza, F. Scaffidi-Argentina, H. Werle, J. Nucl. Mater. 283-287 (Part 2) (2000) 1396-1400.

[9] S. van Tìl, A.J. Magielsen, M.P. Stijkel, H.L. Cobussen, Fus. Eng. Des. 85 (7-9) (2010) 1143-1146.

[10] K. Morita, H. Suzuki, E. Iizuka, T. Hayashi, K. Soda, H. Iwahara, J. Nucl. Sci. Technol. 38 (2001) 930-935.

[11] G. Federici, A.R. Raffray, M.A. Abdou, J. Nucl. Mater. 173 (1990) 185-213

[12] M.H.H. Kolb, R. Knitter, S. van Til, J. Nucl. Mater. 427 (2012) 126-132.

[13] C.E. Jonson, J.P. Kopasz, J. Nucl. Mater. 248 (1997) 91-100.

[14] A. Tsuchiya, T. Hino, Y. Yamauchi, Y. Nobuta, M. Akiba, M. Enoeda, Pl. Fus. Res. 7 (2012) 2405097:1-2405097:3

[15] T. Hino, H. Shibata, Y. Yamauchi, Y. Nobuta, S. Suzuki, M. Akiba, J. Nucl. Mater. 417 (2011) 713-717.

[16] R. Jenkins, R.L. Snyder, Introduction to X-Ray Powder Diffractometry, vol. 138, Wiley Interscience Publications, 1996.

[17] J.A. Fernando, D.D.L. Chung, J. Porous Mater. 9 (2002) 211-219.

[18] J.F. Ziegler, M.D. Ziegler, J.P. Biersack, SRIM-2006.02.

[19] V.Kh. Alimov, M. Mayer, J. Roth, Nucl. Inst. Meth. Phys. Res. B 234 (2005) $169-175$.

[20] M. Mayer, SIMNRA User's Guide, Report IPP 9/113, Max-Planck-Institut fur Plasmaphysik, 1997.

[21] W. Möller, F. Besenbacher, Nucl. Inst. Met. 168 (1-15) (1980) 111-114.

[22] S.T.K. Saito, H. Kawamura, S. Tanaka, J. Nucl. Mater. 253 (1998) 213-218.

[23] D. Vollath, H. Wedemeyer, J. Nucl. Mater. 141-143 (1986) 334-338.

[24] F.C. Kracek, J. Phys. Chem. 34 (1930) 1583-1598.

[25] Sang-Jin Lee, In-Keun Yu, S. Cho, J. Ceram. Process. Res. 12 (2) (2011) 183-186.

[26] X. Gao, X. Chen, M. Gu, C. Xiao, S. Peng, J. Nucl. Mater. 424 (1-3) (2012) $210-215$

[27] P. Bertone, J. Nucl. Mater. 151 (1988) 281-292. 